\title{
PROPÓSITOS DA DIVULGAC̣ÃO CIENTÍFICA NO PLANEJAMENTO DE ENSINO
}

RESUMO: Investigamos o planejamento e os propósitos de uso de materiais de divulgação científica em situações formais de ensino. Para tanto, o estudo contou com a análise de quatrocentas sequências didáticas produzidas por professores de Ciências em um curso de especialização oferecido aos professores da rede estadual de ensino de São Paulo. Trata-se, portanto, de um trabalho de abordagem quali-quantitativa. As análises apontaram oito propósitos distintos de uso da divulgação científica em sala de aula e delinearam, ainda, as ferramentas comunicativas que compõem os suportes de divulgação científica mais utilizados pelos professores.

Palavras-chave: Divulgação científica. Sequência didática. Propósito de ensino. Ferramenta comunicativa. Pesquisa quali-quantitativa.

\section{PROPÓSITOS DE LA DIVULGACIÓN CIENTíFICA EN EL PLANEAMIENTO DE ENSEÑANZA}

RESUMEN: Investigamos el planeamiento y los propósitos de uso de materiales de divulgación científica en situaciones formales de enseñanza. Para ello, el estudio contó con el análisis de cuatrocientas secuencias didácticas elaboradas por profesores de Ciencias en un curso de especialización ofrecido a los profesores del sistema público de enseñanza del estado de São Paulo. Se trata, por lo tanto, de un trabajo de enfoque cualitativo-cuantitativo. Los análisis apuntaron ocho propósitos distintos de uso de la divulgación científica en clase y delinearon, aun, las herramientas comunicativas que componen los soportes de divulgación científica más utilizados por los profesores. Palabras clave: Divulgación científica. Secuencia didáctica. Propósito de enseñanza. Herramienta comunicativa. Investigación cualitativocuantitativa.

\section{PURPOSES OF SCIENTIFIC COMMUNICATION IN THE TEACHING PLANNING}

ABSTRACT: One investigates the planning and purposes of using scientific communication materials in classrooms. For this, we have analyzed four hundred didactic sequences produced by Science teachers in a long term specialization course offered to teachers of

\section{Guilherme da Silva Lima* \\ Marcelo Giordan**}


public teaching system of the state of São Paulo. Therefore, we follow a qualitative-quantitative approach. The analyzes pointed out eight distinct purposes of using scientific communication in the classroom and they also outlined the communication tools as the supports most used by teachers.

Keywords: Scientific popularization. Didactic sequence. Teaching purpose. Qualitative-quantitative research. 


\section{INTRODUÇÃO}

Atualmente a Divulgação Científica (DC) tem destaque no contexto da inclusão científica e tecnológica, de modo que é possível encontrar muitas atividades, sejam realizadas em espaços de educação formal e não-formal, ou ainda aquelas no âmbito da comunicação social realizadas pelos veículos de comunicação.

Por sua relação com a educação científica, a DC também é objeto na pesquisa em Ensino de Ciências por meio de investigações que contemplam espaços típicos de educação não-formal como os museus (NASCIMENTO; COSTA, 2002; BIZERRA, 2009; JACOBUCCI; JACOBUCCI; MEGID NETO, 2009; FALK; NEEDHAM, 2011; MARANDINO, 2015; MONTEIRO; GOUVÊA, 2015; AYDAR 2016), investigações sobre as características e abordagens da DC (ZAMBONI, 2001; DAVIES, 2008; MEDEIROS; RAMALHO; MASSARANI, 2010; SILVA; PIMENTEL; TERRAZZAN, 2011; FRAGA; ROSA, 2015; ERVITI; STENGLER, 2016; LIMA; GIORDAN, 2017) e pesquisas que investigam situações de ensino que estão numa interface entre a educação formal e a educação não-formal (ALMEIDA, 1998; MARTINS, et. al., 2004; CUNHA, 2009; DIAS; ALMEIDA, 2010; ALMEIDA, 2011; ALMEIDA; LIMA, 2016), isto é, situações que apesar de enquadrarem como atividades formais de ensino utilizam, como base de suas atividades, meios e espaços da educação não-formal ou da DC.

Quando a educação formal e a educação não-formal são o foco de discussões e pesquisas é frequente encontrar alguns pontos e conceitos que são disputadas pelas diferentes correntes teórico-metodológicas. Por esse motivo, para estudar essas atividades é conveniente estabelecer alguns parâmetros, dentre eles, a inexistência de uma fronteira absoluta entre a educação informal, educação nãoformal e a educação formal, tal como aponta Smith (2001). O autor destaca que é mais apropriado conceber um espectro de atividades que estão mais próximos ou mais distantes de determinadas práticas. Sendo assim, é possível encontrar atividades educacionais compostas por diversas ferramentas de ensino, independentemente de seu local de origem, como é o caso do uso de suportes de DC em sala de aula.

Pesquisadores da área de Ensino de Ciências têm se dedicado a compreender o funcionamento da DC em situações formais de ensino. Tais investigações são predominantemente estudos de caso, que evidenciam as potencialidades do uso da DC em sala de aula, ao passo que podem ser alcançados diversos objetivos educacionais por meio da inclusão desse suporte nas práticas de ensino (MARTINS, et. al., 2004; PERTICARRARI et. al., 2010; ALMEIDA; GIORDAN, 2014).

Neste trabalho, o objeto da investigação está centrado em situações formais de ensino de Ciências que potencialmente utilizem suportes de DC em atividades de ensino, com o objetivo de investigar os propósitos de ensino presentes em sequências didáticas planejadas por professores de Ciências.

Cabe ressaltar que a DC é produzida em meio a diversas esferas de criação ideológica (BAKHTIN, 2009) e, por isso, pode ter diversas origens e propósitos. Grosso modo, a DC mobiliza atividades relativas à cultura científica e tecnológica, com o intuito de torná-la acessível à sociedade. Apesar de ser produzida visando atingir audiências específicas, a DC nem sempre está restrita a um pequeno ambiente de veiculação e circulação, de modo que as produções podem ser 
utilizadas por sujeitos que não possuem o mesmo perfil do destinatário concebido pelo divulgador (LIMA; GIORDAN, 2017). Tal deslocamento de sujeitos não é um problema em si, mas carece de reformulações e adaptações para que os sentidos presentes na DC não sejam subvertidos, principalmente quando esses sujeitos são professores e estudantes. É importante salientar, que alguns materiais de DC são produzidos para uma audiência que contempla os estudantes, mas nem sempre esta equivalência se mantém. Caso a DC utilizada não tenha sido produzida para uma audiência em fase escolar, o professor tem a função de planejar atividades que supram as possíveis dificuldades geradas pela alteração do destinatário do material.

As variações de sujeitos não são os únicos entraves a serem considerados quando a DC é utilizada em sala de aula, há também a disparidade entre os objetivos informacionais e comunicacionais da DC com os objetivos educacionais da aula de Ciências. Por este motivo, os professores além de selecionar os materiais que serão usados, também devem planejar atividades para que a DC se adeque aos objetivos pedagógicos desenvolvidos por eles e pela escola, tentando evitar a "didatização" direta da DC, conforme defende Cunha (2009).

É nesse contexto que o planejamento do ensino se torna um campo fértil para estudar o uso da DC pelo professor em sala de aula. A elaboração de planos de ensino, que seguem diretrizes teóricas e práticas da atuação do professor em sala de aula, é uma fonte importante das manifestações dos propósitos de ensino dos professores, sendo que a DC pode ocupar um papel importante nesse plano e se constituir como um fator a ser estudado.

No âmbito do ensino, as propriedades da DC como ferramenta cultural (WERTSCH, 1999) podem contribuir para a produção de sentidos para os conceitos científicos, para a contextualização e problematização dos temas estudados, bem como para a discussão da história, filosofia e sociologia da ciência. O uso da DC na educação formal produz um contexto particular de ensino no qual ao menos quatro discursos convivem em sala de aula: o discurso cotidiano, o discurso escolar, o discurso da ciência escolar e o discurso de DC. Esse entrecruzamento é capaz de produzir situações favoráveis à produção de sentidos para os conceitos científicos, bem como estimular a curiosidade e o engajamento dos estudantes nas atividades de ensino.

O uso da DC em sala de aula perpassa por diversos contextos de produção do ensino, bem como o acesso aos recursos utilizados. Ainda que existam etapas anteriores à utilização em sala de aula, como a produção e consumo da DC, é necessário considerar o contato do professor com a DC como pré-requisito para o seu uso em situações de ensino. A rigor, antes de utilizar o suporte de DC, o professor deve conhecê-lo e vislumbrar situações em que esse recurso pode ser utilizado. Para tanto, reconhecemos a necessidade dos professores dominarem tanto determinados propósitos de ensino quanto o uso das ferramentas comunicativas (texto; infográficos; áudios; audiovisuais; etc.) que compõem a DC. Em suma, trata-se de julgar se os suportes de DC podem servir aos propósitos de ensino do professor.

Este trabalho apresenta os resultados de uma pesquisa que investigou os propósitos e a frequência de uso de materiais de DC por professores de ciências, que foram identificados em uma ferramenta de planejamento de ensino produzida em um curso de formação continuada de professores. Delineamos dois objetivos específicos: 
- Realizar o levantamento das ferramentas comunicativas que compõem os suportes de DC utilizados pelos professores;

- Compreender os principais propósitos que o professor atribui aos suportes de DC em sequências didáticas.

Para tanto, baseados em contribuições socioculturais (WERTSCH, 1999), discutiremos a seguir as relações entre DC e sua utilização sala de aula, e analisaremos os planejamentos de ensino de professores que cursaram a Especialização em Ensino de Ciências, oferecido pela Faculdade de Educação da Universidade de São Paulo em parceria com a Rede de Formação Docente do Estado de São Paulo (EEC-FEUSP-REDEFOR).

\section{A DC E SEU USO EM SALA DE AULA}

As situações de ensino são produzidas pela articulação de inúmeras ferramentas que estruturam os processos de ensino e corroboram com a aprendizagem dos estudantes. De modo que o professor é o sujeito responsável pela criação, desenho e planejamento dessas atividades.

Dentre os suportes utilizados, a DC faz parte dos inúmeros recursos que os professores usam para planejar suas aulas e desenhar atividades. Destacamos que a natureza da DC e seus propósitos não estão orientados diretamente para a educação formal, mas o fato é que muitos professores reconhecem as potencialidades de materiais dessa natureza, se apropriaram e estão fazendo uso dos mesmos para o desenvolvimento de atividades de ensino.

Nesse sentido, pesquisadores da área de Ensino de Ciências (ALMEIDA; RINCON, 1993; ALMEIDA, 1998; MARTINS; NASCIMENTO; ABREU, 2004; PINTO, 2009; PERTICARRARI et. al, 2010; ALMEIDA; SORPRESO, 2011; ALMEIDA; GIORDAN, 2014; PAGLIARINI; ALMEIDA, 2015), vêm apontando há mais de duas décadas as potencialidades e as contribuições da leitura em aulas de ciências, bem como do uso de suportes de DC em situações de ensino.

Como contexto de produção de ensino e de pesquisa, Almeida e Ricon (p. 8, 1993) concebem a escola como espaço privilegiado de interações culturais e enfatizam: "a importância de práticas que, além de facilitarem a incorporação do saber científico, podem contribuir para a formação de hábitos e atitudes que permanecerão mesmo após o abandono da escola". Dentro dessas práticas, o uso da DC e do texto literário podem contribuir para o ensino de ciência e para o desenvolvimento de habilidades para a compreensão dos discursos da Ciência, bem como de hábitos e gosto pela leitura.

Assim, as relações entre a ciência e a linguagem emergem como fator relevante para a reflexão acerca da DC, uma vez que é por meio da linguagem que ideias, teorias, e contextos da cultura científica são comunicados. Quando a linguagem está em uso em diferentes esferas de comunicação, deve-se notar que os discursos nelas produzidos não são equivalentes. O discurso de DC e, especialmente, o discurso escolar são fundamentalmente diferentes. Ainda que haja similaridades, os motivos desses sistemas de atividades são distintos, fato que por si evidencia as diferenças entre os discursos, que podem ser confirmados por uma análise mais profunda no âmbito dos seus gêneros discursivos e, consequentemente, dos conteúdos temáticos, estruturas composicionais e estilos. 
Destacamos que as situações formais de ensino não constituem os destinos presumidos pelos autores de DC, assim a DC entra em sala de aula como uma apropriação do professor para corroborar com os processos formativos e com a aprendizagem de conceitos científicos. Portanto, o uso da DC em situações de ensino está em função dos sentidos que este recurso pode gerar. Se por um lado a apropriação da DC pelo professor é o primeiro processo para o uso dessa ferramenta em sala de aula, por outro, a compreensão é o processo que sustenta seu uso, que está orientado para promover a aprendizagem de conceitos, técnicas, habilidades e atitudes referentes à Cultura Científica.

Bakhtin estabelece que compreender é produzir réplicas:

Compreender a enunciação de outrem significa orientar-se em relação a ela, encontrar o seu lugar adequado no contexto correspondente. A cada palavra da enunciação que estamos em processo de compreender, fazemos corresponder uma série de palavras nossas, formando uma réplica. Quanto mais numerosas e substanciais forem, mais profunda e real é a nossa compreensão. (BAKHTIN, p. 137, 2009)

O uso da DC em sala de aula pressupõe ao menos duas situações que favorecem a compreensão, a primeira na dimensão do planejamento da atividade de ensino e a segunda na dimensão da atividade de aprendizagem na própria sala de aula. Tais situações não ocorrem simultaneamente, pois a compreensão na dimensão do planejamento da atividade de ensino é temporalmente a primeira que se realiza, no momento em que o professor analisa a DC e procura potencialidades para seu uso. Em outras palavras, o professor se posiciona frente ao discurso de DC e produz correspondências entre os sentidos ali existentes e os objetivos, conteúdos, abordagens e princípios que orientam a prática escolar. Em seu turno, a compreensão na dimensão da atividade de aprendizagem ocorre simultaneamente ao desenvolvimento das atividades de ensino, isto é, na sala de aula quando os estudantes desenvolvem as propostas e interagem com o discurso de DC.

A compreensão do estudante sobre a DC é diferente da compreensão do professor, essencialmente pelas posições ocupadas no desenvolvimento de suas atividades. Enquanto os estudantes compreendem a DC no plano da sala de aula, isto é, produzindo réplicas referentes aos conceitos científicos ou aos aspectos da cultura científica orientado pelas atividades de ensino; a compreensão do professor é duplamente orientada, isto é, por um lado o professor produz uma compreensão referente aos sentidos da cultura científica, e por outro, ele deve compreender a DC como uma ferramenta cultural que será utilizada em sala de aula em um processo de enculturação científica diverso daquele por ele vivenciado. As distinções entre as compreensões do professor e dos estudantes são devidas a diversos fatores, entre eles o universo de referência de ambos e a capacidade que ambos têm de serem interlocutores do suporte de DC.

Neste sentido, é importante evidenciar os papéis sociais e contextos socioculturais que envolvem os sujeitos na interação verbal: professor e estudantes. No caso do professor, destacamos que a posição ocupada tem duas dimensões: a primeira associada à orientação, tutoria e formação do outro e a segunda associada a quem o professor representa, isto é, todo professor é "professor de" 
física, química, matemática, filosofia, história. Por essa razão, ele é também um representante de determinado campo da cultura científica. Ao pontuar isso, é possível traçar algumas características presentes na compreensão do professor de ciências sobre a DC que estão relacionadas tanto às potencialidades da DC como ferramenta para o ensino e para aprendizagem quanto aos aspectos próprios da cultura científica, seja no âmbito conceitual ou histórico, filosófico, sociológico etc. Desde a perspectiva da ação mediada (WERTSCH, 1999), ferramentas culturais dispõem de potencialidades, ou seja, formas de uso que ampliam e transformam as ações humanas, que estão dialeticamente tensionadas a reduções, ou seja, formas de uso que inibem ações humanas.

Se pautarmos especificamente cada uma dessas dimensões, é possível encontrar indícios mais característicos da compreensão do professor. No caso da DC como ferramenta para o ensino a compreensão está condicionada, sobretudo, à necessidade de promover a enculturação do estudante nas práticas da ciência. Como exemplo, podemos pensar no uso de um livro de DC em sala de aula, que contempla as atividades relacionadas ao planejamento do ensino e às atividades de ensino que visam à ampliação do horizonte cultural dos estudantes. Enquanto o uso da DC permite a ampliação do universo de referência do professor, a atividade de leitura proposta proporciona o desenvolvimento de conceitos científicos, a produção de novos sentidos e o estabelecimento de relações entre a Ciência e outras esferas da produção humana. Para utilizar a DC em sala de aula, as atividades planejadas pelo professor estão condicionadas por fatores como: o tempo necessário para sua realização, a apreensão de conceitos, a adequação do conteúdo e da abordagem metodológica com as propostas de ensino do professor e da escola, dentre outros.

Quando analisamos a interação do professor com a DC a partir do que ele representa, a compreensão está condicionada ao seu domínio da cultura científica. Desse modo, sua compreensão da DC articula relações epistemológicas, históricas, filosóficas, sociológicas, econômicas e políticas da produção científica e da DC. Trata-se de relações entre os aspectos e as condições concretas que carecem de domínio sobre a esfera de referência que está sendo abordada: a Ciência. Em suma, trata-se de uma dimensão da compreensão que é formada pela atuação do professor como sujeito da cultura científica.

Por outro lado, a compreensão do estudante sobre a DC não carrega as mesmas características. Em geral, as réplicas formuladas, os posicionamentos tomados e questionamentos elaborados ficam exclusivamente no plano do referente. Ou seja, os estudantes interagem com os conceitos, histórias, reflexões, posicionamentos presentes na DC, que são objetos discursivos que representam a realidade e/ou a cultura científica.

Cabe ressaltar que, quando a DC entra em sala de aula, já ocorreram alterações em seus propósitos, no caso a DC não chega ao estudante essencialmente como uma ferramenta de comunicação da cultura científica, mas também como uma ferramenta de comunicação da cultura escolar. Neste sentido, o discurso de DC passa a incorporar e produzir o discurso escolar, que por sua vez articulará em sua produção aspectos do discurso de DC, objetivos instrucionais, abordagens metodológicas e os conteúdos associados. 
Assim, a compreensão que o estudante tem da DC é influenciada pela sua extração de seu local de origem e a subsequente realocação em um contexto determinado pelo professor. Em outras palavras, a compreensão que o estudante tem sobre a DC depende da posição e da forma com a qual o discurso de DC é relacionado ao discurso escolar. Portanto, a compreensão que os estudantes têm da DC é condicionada pela apropriação que o professor fez desse suporte.

Os conceitos de domínio e apropriação propostos Wertsch (1999) são capazes de contribuir para essa reflexão acerca da compreensão de professores e de estudantes sobre DC. Para o autor, o domínio de uma ferramenta cultural se refere ao ‘saber como' utilizá-la, ao passo que existem diversos graus de domínio de uma ferramenta. Já a apropriação se refere a tomar uma ferramenta cultural para si, isso implica na autonomia para sua utilização.

Com base nessas contribuições, é possível notar que, na maioria dos casos, a compreensão que os estudantes têm da DC está no plano domínio dessa ferramenta para a aprendizagem, por outro lado o professor se apropria da DC para utilizá-la em situações de ensino.

Ao se apropriar da DC como ferramenta cultural, o professor modifica: seu contexto de uso, que é produzido por uma conjuntura educacional; cria novas ações e atos de interação; delimita os sujeitos correspondentes, que passam a ser exclusivamente os estudantes; reconfigura as agências em questão, não são mais somente a mídia e o discurso de divulgação as principais agências de mediação da cultura científica, mas também o discurso científico escolarizado; e define propósitos para o uso da DC em sala de aula. Enfim, o professor usa a DC autonomamente com o intuito de desenvolver seus propósitos formativos.

Para a interpretação e análise do domínio e da apropriação de ferramentas culturais é pertinente o uso das proposições teórico-metodológicas de Wertsch (1999), que pontua que a investigação da ação mediada deve contemplar cinco elementos: o ato, o propósito, o agente, a agência e a cena.

Nesse trabalho não será possível contemplar uma ampla variedade de contextos, atos e sujeitos, visto que nosso recorte de pesquisa delimita: o uso da DC pelo professor de ciências no planejamento de ensino - ato; propósitos de ensino estabelecidos pelo professor - propósito; situações formais de ensino de ciências - cena; os suportes de DC e suas ferramentas comunicativas - agência; o professor - agente. Outros estudos podem ampliar os elementos da ação mediada se houver diversificação de atos, cenas e agentes no sentido de incluir atividades e contextos de produção e consumo da DC, como por exemplo, as visitas guiadas em espaços de educação não formal e as feiras de ciências.

Cabe destacar que focamos o professor como o principal sujeito do processo de ensino, que por meio do planejamento e desenvolvimento de ações é capaz de inserir a DC em contextos de aprendizagem.

\section{METODOLOGIA}

Com o intuito de analisar os propósitos de ensino dos professores de ciências para o uso de suportes de DC, bem como as ferramentas comunicativas mais utilizadas, esta pesquisa tem como base de dados o curso de Especialização 
em Ensino de Ciências, oferecido pela Faculdade de Educação da Universidade de São Paulo em parceria com a Rede de Formação Docente do Estado de São Paulo (EEC-FEUSP-REDEFOR). Entendemos ser importante uma breve descrição do curso para destacar a natureza dos nossos dados de pesquisa.

O curso foi oferecido, na modalidade semipresencial aos professores da rede estadual de ensino de São Paulo, pela FEUSP em parceria com a Secretaria Estadual de Educação. O curso foi constituído por dez disciplinas, encontros presenciais e a produção de um trabalho de conclusão de curso. Os professores formaram grupos de 25 cursistas que foram orientados por tutores mestres em educação científica.

As disciplinas foram ministradas por meio de um ambiente virtual de aprendizagem (AVA) e compostas por diversos recursos (fóruns, questionários, enquetes, diário de bordo, etc.) e atividades (leitura, interpretação e produção de textos, debates, análise de suportes instrucionais), nos quais materiais de DC estavam frequentemente presentes.

As atividades presenciais, por sua vez, foram organizadas em polos regionais onde os professores se reuniam durante o curso para desenvolverem atividades como análise de suportes para o ensino de ciências e discussões sobre seu uso em sala de aula.

Além disso, o curso de EEC-FEUSP-REDEFOR contou também com atividades que estimulavam e desenvolveram a competência em planejar atividades de ensino pelo professor, que são denominadas sequências didáticas (SD). Ao longo do curso os professores deveriam produzir quatro SD, uma em cada módulo, e é com base nesses dados que desenvolvemos esta investigação.

Com o intuito de delimitar as SD para investigação, inicialmente foram selecionadas amostras de corte e em seguida amostras probabilísticas. O critério para o corte foi estabelecido pelo grupo de pesquisa LAPEQ, com o intuito de selecionar apenas as SD que estavam completas, uma vez que elas eram produzidas no AVA em três etapas e, por diversos motivos, poderiam não ter sido concluídas. Deste modo, foi estabelecido que apenas as SD com notas superiores a 7 seriam utilizadas, o que sinalizava tanto para a conclusão da atividade de planejamento como para a qualidade da SD.

Após a seleção de amostras de corte obtivemos: 285 SD do módulo I, 253 SD do módulo II, 182 SD do módulo III e 170 SD do módulo IV; totalizando 890 SD. Com a definição das amostras de corte o passo seguinte contou com uma seleção probabilística, método que permite a projeção dos resultados para a população investigada. O método probabilístico utilizado foi a amostragem aleatória simples, por isso todas as SD tiveram a mesma probabilidade de serem escolhidas. Para maior coesão dos dados, foram selecionadas, por esse método, 100 SD de cada módulo, assim não haveria o risco de existir a concentração de SD de um determinado módulo, dando, portanto, maior cobertura a todas as fases do curso de formação de professores.

Cabe destacar que as SD foram produzidas no AVA com base no modelo topológico de ensino (GIORDAN, 2008) e contavam com diversos elementos, tais como: caracterização da audiência; problematização; objetivo geral; metodologia de ensino, que era composta por no máximo oito aulas, objetivos específicos, conteúdos e dinâmica das atividades, avaliação, materiais utilizados e referências bibliográficas. 
Devido ao objetivo da investigação, as análises ficaram centradas apenas na metodologia de ensino, nos materiais utilizados, nas referências bibliográficas e nos objetivos específicos. Tal escolha fundamenta-se no pressuposto de que os outros elementos da SD não contemplam o uso de suportes de DC.

Para a organização das SD, bem como para a análise, foi utilizado o software NVIVO $9^{1}$, por meio do qual foi possível codificar as atividades e classificá-las em variáveis categóricas. O software desempenhou a função básica de organizar os dados em um banco correlacionado e ainda verificar a ocorrência de categorias previamente definidas pelo pesquisador em partes do texto não identificadas.

Para a análise dos propósitos de ensino e ferramentas comunicativas que compõem os suportes de DC utilizados no planejamento de ensino, desenvolvemos um estudo piloto com as SD produzidas por um grupo de cursistas. Com esse estudo, foi possível encontrar categorias de análises que foram refinadas após um processo de validação (LIMA, 2016), que envolveu a classificação independente e a construção de consenso sobre a categorização. Com isso, foram encontradas oito categorias que correspondem aos propósitos de ensino planejados pelos professores, quais sejam:

- Contextualização histórica - Neste tipo de atividade, o professor propõe que os estudantes compreendam os contextos que envolveram a cultura científica, o cientista e/ou a conjuntura da sociedade em situações de desenvolvimento científico e tecnológico;

- Explicação - O propósito da atividade é a explicação, explanação, dissertação ou exposição de um tema ou conteúdo específico. O professor, portanto, pretende que os estudantes compreendam conceitos que são abordados por meio do discurso DC;

- Levantamento de concepções - O professor por meio dos materiais de DC visa inventariar (trazer a público) as concepções e percepções que os estudantes têm de determinados temas, contextos, fenômenos etc.;

- Metacognição - Com atividades desta natureza, o professor tem o propósito de fazer com que os estudantes reflitam acerca da produção do conhecimento científico, dos caminhos e procedimentos típicos da Ciência, bem como a comparação de modelos e teorias científicas, o desenvolvimento do questionamento e da reflexão sobre conceitos científicos e sua proposição;

- Pesquisa - A proposta da atividade visa que os estudantes desenvolvam uma pesquisa baseada em suportes de DC. Esta atividade, portanto, irá contribuir especialmente para o desenvolvimento da autonomia do estudante, onde ele seja capaz de encontrar e selecionar suportes que contribuam para sua compreensão sobre determinado tema;

- Produção de material - Propostas que visam à produção de materiais de diversas naturezas por meio de suportes de DC, sejam por meio da escrita de textos, poesias, representações visuais, audiovisuais, produção de diagramas, dentre outras possibilidades;

- Promoção do debate - Esse propósito de ensino é o desenvolvimento da argumentação por meio de suportes de DC disponibilizados pelo professor. A atividade, portanto, pode envolver debates e discussões feitas pelos estudantes; 
- Trabalho de Campo - Atividades que implicam na visita a um espaço físico que desenvolva ações de DC, como os museus, planetários, feiras de ciências ou outras atividades de mesma natureza desenvolvidas em locais próprios. Consideramos, também, visitas museais virtuais, ferramenta que tem sido desenvolvida por muitos museus de ciências.

Os propósitos apresentados acima podem articular diversas características acerca do conhecimento científico, das quais destacamos: semânticas - baseadas nos sentidos expressos e formulados sobre os objetos de estudo; axiológicas - baseadas nos juízos de valores formulados acerca dos objetos de estudo; e epistemológicas - baseadas nas relações entre os saberes e conhecimentos que são articulados nas atividades desenvolvidas.

Além dos propósitos sugeridos por meio do estudo piloto, foi necessária a criação de outras duas categorias que estão associadas aos propósitos de ensino para o uso de suportes de DC, quais sejam:

- Sem especificação - esta categoria visa elencar os suportes de DC que são citados na SD, entretanto não há indicações sobre como ocorre seu uso. No caso, os suportes são indicados como utilizados na SD, no entanto não há detalhamento de seu uso nas dinâmicas das atividades;

- Planejamento - esta categoria contempla os casos em que a DC é utilizada exclusivamente pelo professor durante o planejamento do ensino, isto é, a DC é usada como fonte bibliográfica. Durante as análises essa categoria não foi duplicada na mesma SD, ainda que o professor utilize mais de um tipo de suporte de DC.

Além dos propósitos de ensino, foram elencadas também as principais ferramentas comunicativas que compõem os suportes de DC escolhidos para o desenvolvimento das atividades, quais sejam:

- audiovisual - filmes, vídeos, animações, documentários, jogos, etc.;

- infográficos - imagens, fotografias, desenhos, diagramas e outras representações simbólicas que articulam figuras e a escrita em busca de um significado;

- texto - artigos ou livros publicados em meios impressos de DC;

- visita programada - visita a museu, planetário, jardim botânico, etc.;

- hipertexto - manifestações simbólicas de diversas naturezas disponíveis exclusivamente na web, como os sites, blogs, redes sociais, etc.;

- interação cultural - esta categoria foi utilizada para classificar recursos que não podem ser considerados exclusivamente DC, uma vez que são produções artísticas, musicais, cinematográficas (exceto documentários que foram categorizados como audiovisual), dentre outros, mas ao mesmo tempo têm como principal referente a Ciência. Tal categoria foi estabelecida, com o intuito de contemplar recursos que se constituem em uma interface entre a DC e a produção estética, como é o caso de livros e filmes de ficção científica, músicas ou pinturas sobre a Ciência ou o mundo natural;

- Múltiplos suportes - essa categoria foi utilizada na classificação do uso da DC no planejamento de ensino e apenas em casos nos quais os propósitos de ensino são a pesquisa e a produção de materiais que podem utilizar 
vários suportes para a mesma atividade. Ressaltamos que os múltiplos suportes podem ser utilizados também para a promoção do debate, entretanto, não encontramos casos em que esse era o principal propósito.

As categorias propostas estão de acordo com nosso referencial teórico (WERTSCH, 1999), que estabelece como unidade de análise um pentagrama de elementos que determina a ação mediada, formado pelo: ato, propósito, agência, agente, cena; bem como no Modelo Topológico de Ensino (GIORDAN, 2008) e nos seus desdobramentos para a produção de sequências didáticas. Desse modo, propusemos a investigação dos propósitos e agências (ferramentas comunicativas), que são dois elementos essenciais na elaboração de atividades de ensino. As categorias de análise propostas referem-se, portanto, à variação de propósitos e agências para o uso da DC (ato) pelo professor (agente) em situações de ensino (cena).

Além disso, as análises das ferramentas comunicativas e dos propósitos de ensino das atividades planejadas não foram sobrepostas na mesma categoria, isto é, foi escolhido apenas um propósito e uma ferramenta comunicativa para cada material de DC em uso, ainda que após sua utilização haja desdobramentos de atividades, excetuando os casos já citados. Portanto, cada material de DC terá exclusivamente um propósito de ensino e uma ferramenta comunicativa caso exista mais de um propósito, a análise privilegiou aquele que é imediato e, no nosso entendimento, o principal.

Destacamos que a categorização dos propósitos de ensino foi desenvolvida principalmente por meio da triangulação entre as informações contidas no campo das dinâmicas das atividades e material utilizado presentes na SD. Caso essa triangulação não permitisse determinar o propósito de ensino recorremos aos objetivos específicos da aula. Essa foi uma escolha metodológica baseada no fato de que os objetivos específicos de uma aula não estão no mesmo plano dos propósitos de uma ação docente. De uma maneira geral, uma aula é desenvolvida por meio de diversas ações, por isso os objetivos específicos podem vislumbrar elementos que são promovidos pelo desencadeamento e/ou síntese das ações desenvolvidas.

Para verificar a estabilidade e abrangência das categorias, desenvolvemos um processo de validação (LIMA, 2016) composto por três etapas. A primeira refere-se à validade interna das categorias propostas, que foi realizada por meio da elaboração de constructos analíticos (categorias) baseados nos referenciais teóricos e estudo piloto. A segunda etapa contou com o refinamento e verificação da estabilidade das categorias propostas, que foi aferida por meio da avaliação entre pares, realizada pelo grupo de pesquisadores do Laboratório de Pesquisa em Ensino de Química e Tecnologias Educativas (LAPEQ). A terceira etapa de validação permitiu o último refinamento das categorias, bem como atribuir confiabilidade à análise das 400 SD. Na terceira etapa, selecionamos aleatoriamente $10 \%$ dos dados, isto é $40 \mathrm{SD}$, que foram analisadas por dois pesquisadores. Após essa análise os resultados foram comparados e obtivemos uma correspondência de $89 \%$ dos propósitos de ensino e $91 \%$ das ferramentas comunicativas. Resultado que consideramos bastante satisfatório, uma vez que nas análises buscava-se o principal propósito de ensino, havendo, portanto, subjetividade na interpretação que o pesquisador fez acerca do termo 'principal'. Já com relação às ferramentas comunicativas, a discrepância se deu pela compreensão que os pesquisadores 
tiveram acerca da divulgação científica, isto é, em alguns casos um dos pesquisadores reconhecia o suporte como DC e o outro não.

Portanto, a metodologia aqui empregada apresenta elementos da análise quantitativa por meio de técnica de seleção probabilística de casos representativos de uma amostra, bem como elementos da análise qualitativa por meio da interpretação das ferramentas comunicativas e propósitos de uso da divulgação científica. Tais análises nos permitem interpretar como um grupo relativamente grande e diversificado de professores planeja o uso da DC em situações de ensino.

\section{RESULTADOS E ANÁLISES}

Após as análises, foi possível observar que em apenas 22 SD da amostra de 400 SD não há referências ao uso de DC, seja na atividade de ensino ou no planejamento das aulas. Tais resultados estão distribuídos conforme indicado na tabela 1.

Tabela 1. SD que não usam DC por módulo. Fonte: os autores.

\begin{tabular}{|c|c|}
\hline Módulo & Número de SD que não usam DC \\
\hline 1 & 6 \\
\hline 2 & 8 \\
\hline 3 & 3 \\
\hline 4 & 5 \\
\hline
\end{tabular}

Além disso, foi possível fazer uma descrição detalhada dos propósitos de ensino associados às ferramentas comunicativas que compuseram a DC presente na SD: 
Tabela 2. Cruzamento entre os propósitos de ensino e ferramentas comunicativas de DC.

\begin{tabular}{|c|c|c|c|c|c|c|c|c|}
\hline & Audiovisual & Infográfico & $\begin{array}{c}\text { Visita } \\
\text { programada }\end{array}$ & $\begin{array}{c}\text { Interação } \\
\text { cultural }\end{array}$ & $\begin{array}{l}\text { Múltiplos } \\
\text { suportes }\end{array}$ & Texto & Hipertexto & Total \\
\hline $\begin{array}{c}\text { Contextualização } \\
\text { Histórica }\end{array}$ & 1 & 0 & 0 & 0 & 0 & 2 & 3 & 6 \\
\hline Explicação & 283 & 29 & 12 & 41 & 0 & 55 & 109 & 529 \\
\hline $\begin{array}{l}\text { Levantamento } \\
\text { de concepções }\end{array}$ & 6 & 2 & 0 & 2 & 0 & 2 & 2 & 14 \\
\hline Metacognição & 3 & 0 & 0 & 0 & 0 & 1 & 1 & 5 \\
\hline Pesquisa & 7 & 0 & 3 & 1 & 28 & 11 & 175 & 225 \\
\hline $\begin{array}{c}\text { Produção } \\
\text { de materiais }\end{array}$ & 33 & 10 & 2 & 2 & 3 & 18 & 11 & 79 \\
\hline $\begin{array}{l}\text { Promover } \\
\text { o debate }\end{array}$ & 77 & 5 & 2 & 12 & 0 & 14 & 76 & 186 \\
\hline $\begin{array}{c}\text { Sem } \\
\text { especificação }\end{array}$ & 27 & 0 & 4 & 1 & 0 & 24 & 72 & 128 \\
\hline $\begin{array}{l}\text { Trabalho } \\
\text { de campo }\end{array}$ & 1 & 0 & 18 & 0 & 0 & 1 & 7 & 27 \\
\hline $\begin{array}{l}\text { Planejamento } \\
\text { de ensino }\end{array}$ & 16 & 0 & 2 & 1 & 75 & 27 & 99 & 220 \\
\hline Total & 454 & 46 & 43 & 60 & 106 & 155 & 555 & 1419 \\
\hline
\end{tabular}

Fonte: os autores.

Destacamos que suportes de DC apareceram 1.419 vezes nas SD investigadas (média: 3,5 suportes de DC por SD), de modo que 1.291 representam o total de suportes utilizado com propósitos de ensino específicos no planejamento de ensino (média: 3,2 suportes de DC por SD), isto é, excluídos aqueles que foram classificados como sem especificação. Tal informação nos indicia que os professores de Ciências utilizam frequentemente suportes de DC em suas aulas, uma vez que o planejamento de atividades expresso nas SD deve estar relacionado às práticas desenvolvidas em sala de aula. Tais resultados apontam para uma forte relação entre a DC e a educação formal, pois observamos a ocorrência abundante de proposições de planos de ensino que indicam possibilidades privilegiadas da abordagem da DC em sala de aula.

Os resultados trazem outras informações relevantes acerca do planejamento de ensino. A primeira é que, como a categoria planejamento de ensino não foi duplicada na mesma SD, ela indica o número de SD que utilizaram a DC como fonte 
bibliográfica: 220 SD (55\% da amostra). Dado que evidencia não somente o uso da DC em situações de ensino, como também o valor atribuído pelos professores a esse tipo de recurso como fonte de referência para o planejamento.

Os propósitos de ensino, por sua vez, expressam a variedade de formas com que a DC pode ser utilizada em sala de aula, a multiplicidade de usos já foi apontada em outras investigações (SILVA; KAWAMURA, 2001; MARTINS; NASCIMENTO; ABREU, 2004; FERREIRA; QUEIROZ, 2012), no entanto não com a profundidade que apresentamos. Para melhor compreender os propósitos e ferramentas comunicativas para o uso da DC em situações de ensino é possível segregar as categorias investigadas e analisá-las com base em suas características, como apresentado a seguir.

A distribuição dos propósitos de ensino destaca a explicação, que representa $49,4 \%{ }^{2}$ dos propósitos de ensino para o uso de suportes de DC em sala de aula, evidenciando, portanto, o aspecto conceitual da DC, ou seja, a DC é usada em sala de aula como recurso que fomenta o ensino e a aprendizagem de determinados conceitos, métodos ou práticas da cultura científica. Portanto, a DC é utilizada para contemplar aspectos semânticos que envolvem os assuntos trabalhados. Podemos também inferir que os professores optam por atribuir aos suportes de DC a função de criar relações de causalidade entre fenômenos e conceitos, como uma ferramenta auxiliar para a produção de significados. Tal propósito também pode estar associado com as próprias características de alguns suportes de DC, que frequentemente é composto por diversas informações, definições e explicações sobre o assunto abordado (LOBO; MARTINS, 2013 p. 13)

Outras duas categorias que se destacam são pesquisa e promoção do debate, que representam, respectivamente, $21 \%$ e $17,4 \%$ dos propósitos de ensino para o uso de DC em situações de ensino. Relevante notar que, logo após a principal categoria, explicação - que tende a concentrar as abordagens do uso da DC em discursos monológicos, centrado no discurso de DC e nos conceitos por ele contemplado - estejam as categorias que indicam uma posição mais ativa dos estudantes, que possibilita a ocorrência de diversas abordagens comunicativas. A pesquisa e a promoção do debate, em contrapartida à explicação, deslocam parcialmente o centro de referência da interação, que passa a ser compartilhado pelos estudantes.

No caso da promoção do debate, o foco da atividade de ensino está na interpretação que os estudantes têm daquilo que foi trabalhado, isto é, como ele interpreta a DC. Tal interpretação não ocorre de modo arbitrário e a autonomia dos estudantes é parcial, já que normalmente é o professor quem seleciona os suportes de DC que serão utilizados. É importante ressaltar que a interpretação que os estudantes fazem nem sempre é homogênea e padronizada, ainda que seja o mesmo material utilizado, os sentidos produzidos pelos estudantes variam de acordo com os contextos socioculturais por eles vivenciados (VIGOTSKI, 2009). O uso desse propósito de ensino está fundamentado, portanto, na esfera semântica, isto é, na compreensão dos significados dos conceitos e das práticas da cultura científica.

No propósito pesquisa, ocorre algo semelhante, todavia a autonomia dos estudantes é muito maior, uma vez que podem selecionar os materiais que serão utilizados. Desse modo, estes escolhem também os discursos e as concepções que 
adotarão. Portanto, ao utilizar esse propósito, o centro de referência da interação é deslocado para o estudante e comporta ao menos duas facetas: a semântica, que é orientada pela compreensão que o estudante tem dos conceitos e dos referentes tratados pela DC; e a axiológica, que é orientada pelos juízos de valores que orientam as escolhas e as posições tomadas frente aos referentes abordados pela DC. Em casos especiais, pode haver também outra faceta, a epistemológica, que considera a origem, coesão e validade de determinados argumentos e teorias apresentada pela DC. Apesar de ser possível, a modalidade epistemológica não possui posição central na escolha dos estudantes, pelo simples fato de estarem em um processo de aprendizagem de nível básico e sua compreensão acerca de uma teoria geralmente se limita aos conceitos que são estudados em casos particulares.

Os propósitos de ensino produção de materiais e trabalho de campo não possuem grande representatividade das propostas, de modo que correspondem a, respectivamente, $7,4 \%$ e $2,5 \%$ dos propósitos planejados. Ao contrário das categorias analisadas anteriormente, não é possível evidenciar as principais esferas que são articuladas pelas categorias producão de materiais e trabalho de campo, devido à variedade de atividades e suas particularidades.

Podemos contrapor na categoria produção de materiais duas atividades: produção de cartazes e produção de poesias; ambas fazem parte da mesma categoria de propósitos de ensino, todavia articulam esferas diferentes. Na produção de cartazes, os aspectos semânticos são muito importantes e não podem ser negligenciados em nenhuma hipótese, ao contrário da poesia, que pode se destacar por suas características estéticas que, por vezes, podem acarretar no prejuízo de rigor semântico. Com o trabalho de campo, ocorre o mesmo. Um trabalho de campo realizado em um espaço de educação não formal, por exemplo, geralmente possui tantas atividades diferentes que não é possível indicar as principais esferas articuladas em uma visita. Nesse sentido, se for o desejo do professor ou pesquisador investigar as características desses propósitos, faz-se necessário uma observação mais detalhada sobre os suportes utilizados, materiais produzidos e exposições visitadas.

O último grupo de propósitos de ensino concentra as categorias levantamento de concep̧cões, contextualização histórica e metacognição. As três categorias tiveram baixa frequência de uso, correspondendo a respectivamente 1,3\%,0,6\% e $0,5 \%$ dos principais propósitos das atividades planejadas pelos professores. Devido à baixa frequência de uso desses propósitos como estruturantes principais das atividades planejadas, podemos considerar seu uso como um evento raro, fato que evidencia as dificuldades dos professores em desenvolver determinadas atividades. Tais dificuldades podem estar relacionadas tanto ao domínio desses propósitos de ensino quanto à seleção de suportes de DC e ferramentas comunicativas que permitam e fomentem esse tipo de atividade. É relevante ressaltar que essas três categorias são aquelas que possuem grande representatividade dos aspectos epistemológicos e que em tese podem contribuir para o desenvolvimento de atividades fomentadoras da formação de concepções sobre ciências.

Ressaltamos que esses propósitos de uso da DC, ainda que raros, podem contribuir significativamente com o ensino de ciências, uma vez que permite novas abordagens sobre temáticas científicas. Tais propósitos dialogam com os resultados apresentados por Pinto (2009), que destaca novas potencialidades do 
uso da DC em sala de aula, como: ênfase em aspectos processuais da ciência e não nos resultados da ciência; reflexões sobre a existência humana e suas contradições; centralidade na reflexão sobre a humanização e não na transmissão de conteúdos da ciência, embora esses também compareçam às obras, sem prejuízos; reflexão sobre a condição humana do cientista, apresentado como um sujeito inserido no mundo e numa teia de relações sociais, políticas e afetivas; dentre outras.

O levantamento de concepcões provavelmente é a categoria de maior abrangência e contempla tanto características semânticas, quanto características axiológicas e epistemológicas do tema abordado. Quando o professor usa esse propósito de ensino, evidentemente quer saber o que os estudantes conhecem sobre determinado tema ou fenômeno, bem como os significados que eles atribuem a estes, isto é, os aspectos semânticos estão em evidência. Por outro lado, quando os estudantes dominam um conhecimento de qualquer natureza acerca dos temas trabalhados, há necessariamente características axiológicas: se o estudante domina, então algum juízo de valor ele faz sobre o conhecimento. Por fim, destaca-se a existência de relações entre as concepções dos estudantes e os conteúdos teoricamente estruturados pelas respectivas áreas disciplinares, relações que, ainda que sejam equivocadas do ponto de vista científico, são relações epistemológicas. Na verdade, a existência dessas três características, no propósito levantamento de concepçôes, ocorre especialmente devido ao sujeito que detém a fala que, nesse caso, é principalmente o estudante. O discurso de DC fica em segundo plano para que as concepções emerjam no decorrer da atividade. $\mathrm{O}$ discurso de DC é, portanto, um iniciador que permite uma série de contribuições e desdobramentos temáticos e teóricos manifestados pelos estudantes.

Finalmente, sobre as categorias contextualização histórica e metacognição, é importante salientar que, em ambas, a característica principal da atividade é o desenvolvimento de aspectos epistemológicos do assunto. No caso da contextualização histórica, o professor visa desenvolver os contextos socioculturais que influenciaram na produção do conhecimento científico. $\mathrm{O}$ foco principal não está centrado nos significados dos conceitos, quão menos na validação da proposta científica, mas sim na conjuntura que corroborou para o desenvolvimento científico e tecnológico. Em seu turno, com a metacognição, o professor visa à reflexão sobre o conhecimento e sua estrutura conceitual, atividade que está ligada diretamente aos aspectos epistemológicos do conteúdo, ao passo que as características semânticas e axiológicas podem estar presentes, mas são secundárias.

Com relação à frequência das ferramentas comunicativas utilizadas, é possível notar a alta representatividade dos meios audiovisuais, que perfazem 38,4\% dos suportes planejados para o uso em sala de aula. A categoria hipertexto, por sua vez, representa $35,9 \%$ das ferramentas comunicativas que compõem os suportes utilizados.

Quanto aos audiovisuais, estudos recentes têm discutido suas possibilidades e contribuições com a educação científica, seja por meio da ficção científica seja por meio de documentários (PIASSI, 2013; MARCELLO; RIPOLL, 2016).

$\mathrm{Na}$ sequência, textos e interação cultural representam 9,7\% e 5,4\% das ferramentas comunicativas utilizadas nas SD. As ferramentas comunicativas menos utilizadas são os infográficos, com 4,3\%, a vista programada, com 3,5\%, e os múltiplos suportes, com apenas $2,9 \%$ de planejamento de uso. Relevante notar que, apesar de existir muitas imagens disponíveis, bem como sínteses organizadas por meio 
de infográficos, essas ferramentas comunicativas não são frequentemente utilizadas por professores, que preferem aqueles que são produzidos especialmente pela linguagem verbal, seja ela escrita ou falada. Ressaltamos ainda que os suportes de divulgação científica são frequentemente compostos por infográficos e imagens, que são utilizadas para representar situações comuns para os destinatários presumidos ou mesmo para exemplificar situações discutidas (ALMEIDA; SORPRESO, 2011; GRILLO, 2010). No entanto, o baixo índice de planejamento com essa ferramenta comunicativa pode apresentar as limitações metodológicas da investigação aqui apresentada, uma vez que não foi possível verificar os 710 suportes entre textos e hipertextos para aferir a sua composição por infográficos.

O cruzamento de propósitos e ferramentas comunicativas apresentados na tabela 2 nos revela características importantes acerca do planejamento do uso de DC em sala de aula. Para o propósito explicação, aquele que está mais presentes nas SD, os professores têm grande preferência pelo audiovisual $(53,5 \%)$, seguido do hipertexto $(20,6 \%)$.

Um dos motivos da grande presença do audiovisual na explicaşão provavelmente está relacionado às formas tradicionais de compreender o que é uma explicação: uma apresentação expositiva, em que os estudantes passivamente prestam atenção na exposição, portanto, uma atividade desenvolvida baseada no controle do comportamento dos estudantes. Além disso, as ferramentas comunicativas classificadas como textos estão concentradas no propósito de ensino explicação, outro indício da concepção de explicação como exposição, visto que durante a leitura do texto existe especialmente o discurso do autor no contexto de sala de aula.

O planejamento de uso de hipertextos em atividades de pesquisa também se destaca, representando 77,8\% das ferramentas comunicativas. Entendemos que essa representatividade é decorrente das ferramentas proporcionadas pelos hipertextos como os hiperlinks que permitem uma navegação fácil pelos diversos assuntos abordados. Tal ferramenta corrobora com o desenvolvimento de uma pesquisa, visto que os estudantes podem buscar informações disponíveis em diversos locais da rede mundial de computadores.

Ainda sobre a categoria pesquisa, é relevante notar que essa categoria concentra a maior parte do uso de múltiplos suportes em sala de aula, fato que fortalece nossa interpretação, visto que, para ser realizada uma pesquisa, é necessária uma variedade de fontes, característica que ganha destaque especialmente com os suportes de hipertexto e múltiplos suportes.

Outro resultado que nos chama a atenção é a concentração do uso da interação cultural para o propósito explicação (68,3\%). É difícil encontrar quais os fatores para essa concentração especialmente devido à natureza complexa dessa ferramenta comunicativa. Esse tipo de ferramenta é produzido em meio a uma tensão irredutível entre forma e conteúdo. Se, por um lado, o acabamento estético é fundamental, por outro, a manutenção dos sentidos não pode ser menosprezada. Em meio a essa disputa, são necessárias adaptações que, por vezes, privam o acabamento estético como, por exemplo, a construção de rimas que podem poetizar excessivamente um conceito a ponto de ressignificá-lo ou mesmo as famosas explosões com a propagação de som no espaço interestelar. Com essas 
adaptações, podem existir erros conceituais que, por sua vez, faz-nos questionar o uso desse suporte para a explicação.

Apesar disso, tendemos a crer que o uso da interação cultural com propósito de explicação está relacionado à exposição do objeto de estudo. Categorizamos como explicação todas as ações docentes que visam expor ou dissertar assuntos para que os estudantes compreendam suas características. Nesse sentido, suportes que contam com a interação cultural poderiam ser um iniciador, uma ferramenta que ofereça elementos para que o professor articule assuntos e posições presentes no suporte com aquelas relacionadas aos conteúdos estudados.

Para promoção do debate, a maior parte das sequências didáticas utilizou as ferramentas comunicativas audiovisual (41,4\%) e hipertextos (40,8\%). Cabe ressaltar que essa categoria melhor representa a distribuição de uso dos suportes planejados pelos professores.

O propósito produção de materiais foi o único que contemplou o uso de todas as ferramentas comunicativas detectadas. Tal fato é justificado por este ser o propósito mais versátil, visto que contempla a produção de relatório, cartaz, produções artísticas como poesia e teatro, dentre outras.

Escolhemos não fazer inferências acerca dos propósitos levantamento de concepções, contextualização histórica e metacognição devido à baixa incidência destes como principais propósitos de ensino. Entretanto, destacamos a necessidade de aprofundar as investigações sobre o uso de DC com esses propósitos, pois ainda que existam poucos casos quando focamos o principal propósito, isso não acontece quando tentamos investigar todos os propósitos de ensino que o professor tem ao desenvolver uma atividade ${ }^{3}$.

Com respeito ao uso da DC para o planejamento de ensino, notamos que o professor tem preferência pelas ferramentas comunicativas hipertexto e múltiplos suportes. Tais preferências provavelmente estão relacionadas ao acesso aos suportes de DC pela internet no caso do hipertexto e à variedade de fontes de informações proporcionada pelos múltiplos suportes.

A análise dos cruzamentos nos mostra uma grande concentração de ferramentas comunicativas utilizadas, o motivo disso pode estar relacionado: à facilidade de acesso do professor; ao domínio e falta de domínio de determinadas linguagens e formas de representação simbólica; e à objetividade de determinadas ferramentas. Nesse trabalho, as informações coletadas e os dados obtidos não são suficientes para investigar os motivos adotados pelos professores para selecionar os suportes utilizados, todavia, é uma pergunta que pode ser fruto de investigação em trabalhos futuros.

\section{CONSIDERAC̣ÕES FINAIS}

Atividades que envolvem o uso de DC foram frequentes nos casos analisados, de modo que entre as 400 SD, havia apenas 22 que não utilizaram ou não especificaram o uso de suportes de DC no planejamento de ensino. Esta frequência evidencia indícios da eficiência do uso desse tipo de recurso no ensino e na aprendizagem, ou ao menos que os professores de Ciências consideram eficazes 
os usos da DC em situações de ensino de Ciências. Nossos resultados por serem decorrentes de planos de ensino indiciam o potencial da abordagem da DC na sala de aula, pois a proposição do plano não segue necessariamente sua aplicação. Ainda assim, são resultados que destacam o papel relevante da DC na enculturação científica desde a educação escolar, na perspectiva do professor de Ciências.

Além disso, é relevante frisar, que o uso de DC em sala de aula não pode ocorrer de modo direto e, por isso, tem que passar por um processo de ressignificação feito pelo professor, na qual a DC deixa de ter seus fins específicos e passa a configurar propósitos de ensino, dentre os quais este trabalho aponta oito: contextualização histórica, explicação, levantamento de concepçôes, metacognição, pesquisa, produção de materiais, promoção do debate e trabalho de campo. No entanto, destacamos que pode haver outros propósitos que ainda não foram observados. As categorias apresentadas nesse estudo apontam novas possibilidades de uso para a DC em situações de ensino. Ao comparar os propósitos de ensino com os objetivos relatado por pesquisadores da área (FERREIRA; QUEIROZ, 2012), podemos notar uma ampliação das possibilidades de uso da DC em situações de ensino. Temos ciência de que não investigamos questões relativas ao interesse, motivação, ou ainda outros hábitos (como a leitura) que podem ser desenvolvidos com a DC. Salientamos, porém, a necessidade de estabelecer critérios que de fato diferenciem as modalidades de atividades que a DC pode promover, como os propósitos de ensino.

A metodologia de pesquisa empregada, com características qualitativa e quantitativa, mostrou-se consistente e capaz de interpretar nuances importantes de um conjunto extenso de dados. Aliado ao fato de a metodologia de ensino empregada no EEC-FEUSP-REDEFOR ter contemplado a estreita vinculação entre os referenciais teóricos do Ensino de Ciências, bem como do planejamento de ensino, e a prática de sala dos professores participantes do programa, podemos inferir que os resultados aqui apresentados são representativos dessa amostra de professores participantes no que diz respeito à sua atuação no cotidiano escolar. Dessa forma, podemos inferir que os suportes de DC desempenham propósitos diversificados e estão fortemente inseridos nas práticas de ensino desses professores em sala de aula. Ressaltamos que este objeto de estudo carece de maiores investigações, como o acompanhamento do desenvolvimento da SD que usa suportes de DC em suas atividades propostas.

Com este trabalho, espera-se contribuir para o aprofundamento da investigação sobre práticas de ensino e uso de suportes para o ensino de ciências em situações formais de ensino. Além disso, as categorias de planejamento de uso da DC no planejamento de ensino podem contribuir com os professores para inserir e propor novas atividades.

Por fim, destacamos que o uso de suportes de DC em situações de ensino pode corroborar para a produção de um novo contexto de ensino e aprendizagem promovendo a produção de sentidos pelos estudantes, assim como pesquisadores da área têm apontado (PINTO, 2009; GIORDAN e CUNHA, 2015). 


\section{REFERÊNCIAS}

ALMEIDA, M. J. P. M.. O texto escrito na educação em física: enfoque na divulgação científica. In: ALMEIDA, M. J. P. M.; DIAS, R. H. C. Linguagens, leituras e ensino da ciência. Campinas: Mercado das letras, 1998.

ALMEIDA, M. J. P. M.; RINCON, A. E. Divulgação científica e texto literário: uma perspectiva cultural em aulas de física. Caderno Catarinense de Ensino de Física. v. 10, n. 1, 7-13, 1993.

ALMEIDA, M. J. P. M.; SORPRESO, T. P. Dispositivo analítico para compreensão da leitura de diferentes tipos textuais: exemplos referentes à física. Pró-Posições, v. 22, p. 83-95, 2011.

ALMEIDA, S. A. Interações e práticas de letramento mediadas pela revista ciência hoje das crianças em sala de aula. Tese (Doutorado) - FE/USP, São Paulo. 2011.

ALMEIDA, S. A.; GIORDAN, M. A revista Ciência Hoje das Crianças no letramento

escolar: a retextualização de artigos de divulgação científica. Educação \& Pesquisa, São Paulo, v. 40, n. 4, p. 999-1014, 2014. http://dx.doi.org/10.1590/s1517-97022014041219

ALMEIDA, S. A.; LIMA, M. E. C. C. Cientistas em Revistas: Einstein, Darwin e Marie Curie na Ciência Hoje das Crianças. Ensaio: Pesquisa em Educação em Ciências (Belo Horizonte), v. 18, n. 2, p. 29-47, 2016.

AYDAR, M. C. Examining the Effect of Our World Exhibit on Student Visitors: A Science Center Case. Science Education International, v. 27, n. 3, p. 419 - 436, 2016.

BAKHTIN, M. M. (VOLOCHÍNOV). Marxismo e Filosofia da Linguagem: problemas fundamentais do método sociológico na ciência da linguagem. 13ª ed. São Paulo: Hucitec, 2009.

BIZERRA, A. F. Atividade de aprendizagem em museus de ciências. 2009. 155 f. Tese (Doutorado em Educação) - Faculdade de Educação, Universidade de São Paulo, São Paulo, 2009.

CUnHA, M. B. A percepção de Ciência e Tecnologia dos estudantes do ensino médio e a divulgação científica. Tese (Doutorado) - FE/USP, São Paulo. 2009.

DAVIES, S. R. Constructing Communication : Talking to Scientists About Talking

Published to the Public. Science Communication, 29, p. 413-434, 2008.

DIAS, R. H. A.; ALMEIDA, M. J. P. M.. Especificidades do jornalismo científico na leitura de textos de divulgação científica por estudantes de licenciatura em física. Revista Brasileira de Ensino de Física, v. 31, n. 4, 01-12, 2010.

ERVITI, M. C.; STENGLER, E. Online science videos: an exploratory study with major professional content providers in the United Kingdom. Journal of Science Communication, v. 15, n. 06, p. 01-15, 2016.

FALK, J.H.; NEEDHAM, M. D. Measuring the impact of a science center on its community. Journal of Research in Science Teaching, 48, p. 01-12, 2011.

FERREIRA, L. N. A.; QUEIROZ, S. L. Textos de Divulgação Científica no Ensino de Ciências: uma revisão. Alexandria: Revista de Educação em Ciência e Tecnologia, v.5, n.1, p.3-31, 2012.

FRAGA, F. B. F. F.; ROSA, R. T. D. Microbiologia na revista Ciência Hoje das Crianças: análise de textos de divulgação científica. Ciência \& Educação, v. 21, n. 1, p. 199-218, 2015.

GIORDAN, M. Computadores e linguagens nas aulas de ciências: Uma perspectiva sociocultural para compreender a construção de significados. 1a ed. Ijuí - RS: Editoria da UNIJUÍ, 2008.

GIORDAN, M. E CUNHA, M.B. Divulgação Científica na Sala de Aula: perspectivas e possibilidades. Ijuí/RS: Ed da UNIJUÍ. 360 p., 2015.

GRILLO, S. V. C. Enunciados verbo-visuais na divulgação científica. Revista da ANPOLL, v. 27, p. 215-243, 2010. 
JACOBUCCI, D. F. C.; JACOBUCCI, G. B.; MEGID NETO, J. Experiências de Formação de Professores em Centros e Museus de Ciências no Brasil. Revista Electrónica de Enseñanza de las Ciencias, v. 8, p. 118-136, 2009.

LIMA, G. S. O professor e a divulgação científica: apropriação e uso em situações formais de ensino. (Tese de doutorado) FE/USP, São Paulo, 2016. Recuperado de

http://www.teses.usp.br/teses/disponiveis/48/48134/tde-16082016-093959/pt-br.php

LIMA, G. S.; GIORDAN, M. Características do discurso de divulgação científica: implicações da dialogia em uma interação assíncrona. Investigações em Ensino de Ciências, v. 22, n. 2, p. 83-95, 2017. http://dx.doi.org/10.22600/1518-8795.ienci2017v22n2p83

LOBO, M.; MARTINS, I. Representações Sobre Alimentação e Ciência em um Texto de Divulgação Científica: implicações para a educação em ciências. Alexandria: Revista de Educação em Ciência e Tecnologia, v.6, n.3, p. 3-26, 2013.

MARANDINO, M. Análise sociológica da didática museal: os sujeitos pedagógicos e a dinâmica de constituição do discurso expositivo. Educação e Pesquisa - Revista da Faculdade de Educação da USP, v. 41, p. 695-712, 2015.

MARCELO, F. A.; RIPOLL, D. A educação ambiental pelas lentes do cinema documentário. Ciência \& Educação, v. 22, n. 4, p. 1045-1062, 2016.

MARTINS, I.; NASCIMENTO, T. G.; ABREU, T. B. Clonagem na sala de aula: um exemplo do uso didático de um texto de divulgação científica. Investigações em Ensino de Ciências, RS, Brasil, v. 9, n. 1, p. 1-20, 2004.

MEDEIROS, F. SN. S.; RAMALHO, M.; MASSARANI, L. A ciência na primeira página: análise das capas de três jornais brasileiros. História, ciências, saúde - Manguinhos, v. 17, n. 2, p. 439-454, 2010. MONTEIRO, R. ; GOUVÊA, G. . Tempo no museu e o museu no tempo. Ciência \& Educação, v.21, p. 234-253, 2015.

NASCIMENTO, S. S.; COSTA, C. B. Um final de semana no zoológico: um passeio educativo? Ensaio: Pesquisa em Educação em Ciências (Belo Horizonte), v. 4, n. 1, p. 01-14, 2002.

PAGLIARINI, C. R.; ALMEIDA, M. J. P. M. Leituras por alunos do ensino médio de textos de cientistas sobre o início da física quântica. Ciência \& Educação, v. 22, n. 2, p. 299-317, 2016.

PAGLIARINI, C. R.; ALMEIDA, M. J. P. M. Física quântica numa leitura de divulgação científica no início do Ensino Médio: manifestações dos estudantes. In: GIORDAN, M.; CUNHA, M. B. Divulgação científica na sala de aula: perspectivas e possibilidades. Ijuí: Editora Unijuí, 2015. p. 249-284.

PIASSI, L. P. Clássicos do cinema nas aulas de ciências - a física em 2001: uma odisseia no espaço. Ciência \& Educação, v. 19, n. 3, p. 517-534, 2013.

PINTO, G. A. Literatura não-canônica de divulgação científica em aulas de ciências. Ensaio: Pesquisa em Educação em Ciências, v.11, n.02, p.299-317, 2009.

PERTICARRARI, A.; TRIGO, F. R.; BARBIERI, M. R. COVAS, D. T. O uso de textos de divulgação científica para o ensino de conceitos sobre ecologia a estudantes da educação básica. Ciência \& Educação, v. 16, n. 2, p. 369-386, 2010.

SILVA, J. A.; KAWAMURA, M. R. D. A natureza da lua: uma atividade com textos de divulgação científica em sala de aula. Caderno Catarinense de Ensino de Física, v. 18, n. 3, p. 316-339, 2001.

SILVA, L. L.; PIMENTEL, N. L.; TERRAZZAN, E. As analogias na revista de divulgação científica Ciência hoje das crianças. Ciência \&. Educação, v. 17, n. 1, p. 163-181, 2011.

SMITH, M. K. Non formal education. Infed. 2001. Disponível em: <http://www.infed.org/ biblio/b-nonfor.htm\#idea>. acesso: 14/08/2013.

VIGOTSKI, L. S. A construção do pensamento e da linguagem. $2^{\mathrm{a}}$ ed. São Paulo: Martins Fontes, 2009. 
WERTSCH, J. La Mente en Acción. Buenos Aires: Aique, 1999.

ZAMBONI, L. M. S. Cientistas, jornalistas e a divulgação científica: subjetividade e heterogeneidade no discurso de divulgação científica. Campinas: Autores associados, 2001.

\section{NOTAS}

${ }^{1}$ Nvivo é software desenvolvido pela QSR para suportar métodos de pesquisa qualitativos e mistos, que permite o agrupamento das informações de pesquisa, bem como sua classificação, categorização e organização.

${ }^{2}$ Cabe ressaltar que para o cálculo da representatividade de uso dos propósitos de ensino consideramos somente a frequência absoluta dos propósitos, excetuando as categorias sem especificaşão e planejamento de ensino.

${ }^{3}$ Durante o desenvolvimento da pesquisa, fizemos exercícios, inclusive na etapa de validação, para demarcar todos os propósitos de ensino presentes nas atividades planejadas, todavia, devido aos nossos objetivos, foi apenas um exercício analítico que não gerou resultados suficientes para uma análise conclusiva. Destacamos que, nesses exercícios, encontramos diversas vezes os propósitos levantamento de concepções, contextualização histórica e metacognição, mas como propósitos secundários e/ ou desdobramento das atividades de ensino. Esses achados indiciam a necessidade do professor valorizar atividades de ensino dessa natureza.

\section{Submetido em 29/05/2017}

Aprovado em 18/10/2017

\section{Contato:}

Guilherme da Silva Lima

Departamento de Física, Instituto de Ciências Exatas e Biológicas (ICEB), Campus Morro do Cruzeiro,

Universidade Federal de Ouro Preto.

CEP: 35400-000. Ouro Preto, MG - Brasil.

\section{Marcelo Giordan}

Departamento de Metodologia de Ensino e Educação Comparada

Faculdade de Educação

Universidade de São Paulo.

Av. da Universidade, 308, Cidade Universitária.

CEP: 05508-040. São Paulo, SP - Brasil. 